\title{
INCIDENCE OF HELICOBACTER PYLORI WITH ACID PEPTIC DISEASE AND MALIGNANT CONDITIONS OF UPPER GASTROINTESTINAL TRACT IN A TERTIARY CENTRE - A PROSPECTIVE STUDY
}

\author{
Karunamoorthy Rajachidambaram¹, Dinkaran Kaarthesan ${ }^{2}$
}

${ }^{1}$ Associate Professor, Department of General Surgery, Chennai Medical College Hospital \& Research Centre, Irungalur, Trichy. ${ }^{2}$ Associate Professor, Department of General Surgery, Chennai Medical College Hospital \& Research Centre, Irungalur, Trichy.

\section{ABSTRACT}

\section{AIMS AND OBJECTIVES}

To study the prevalence of Helicobacter pylori in patients with dyspepsia undergoing upper gastro intestine endoscopy in Chennai Medical College Hospital and Research Institute and to study the association of Helicobacter pylori with Acid peptic diseases and Malignant conditions of upper gastro intestine tract.

\section{MATERIALS AND METHODS}

389 cases of dyspepsia, studied clinically as per the proforma over a period of three years from July 2012 to April 2015, were subjected to upper gastrointestinal endoscopy under topical anaesthesia, during which 4 biopsies, two each from the antrum and the pathological areas were taken. Two biopsy specimens, one of the antral area and the other of the pathological finding were immediately subjected to rapid urease test. Positive test for Helicobacter pylori was indicated by change in colour of the medium from yellow to pink or red. The other two biopsy specimens were sent for routine histopathology and special staining with Giemsa stain. The case was taken as Helicobacter pylori positive when the rapid urease test and/or histopathological examination was positive.

\section{RESULTS}

Out of 389 patients with mean age of 41.8 years; 172 patients were diagnosed to have been infected with Helicobacter pylori (44.21\%). Out of 49 patients with gastric and duodenal ulcers, 37 patients were infected with Helicobacter pylori (75.51\%); 22 out of 25 patients (88\%) with duodenal ulcers and 10 out of 14 patients $(71.4 \%)$ with gastric ulcers were positive for $\mathrm{H}$. pylori, while only 8 out of 10 patients $(80 \%)$ with gastric cancer were positive for $\mathrm{H}$. pylori. Out of remaining 340 patients, out of which 43 were found to be positive for Helicobacter pylori infection (33.85\%) and 213 patients with gastritis/duodenitis, out of which 92 were infected with Helicobacter pylori (43.19\%). There were 127 patients with normal endoscopic findings.

\section{CONCLUSION}

In this study, we found that Helicobacter pylori was consistently associated with peptic ulcer disease and malignant conditions of upper GI tract, which is in broad agreement with the studies done earlier. Thus we conclude that, Helicobacter pylori infection may have a major role in the aetiopathogenesis of peptic ulcer disease and malignant conditions of upper GI tract here appears to be no significant association between Helicobacter pylori infection and unexplained dyspepsia. Hence, we recommend eradication of the bacteria only in patients positive for the bacterium, who have peptic ulceration.

The cases positive by rapid urease test were found positive from biopsy also. Peter C Robin's dictum: "If a person with peptic ulcer disease is shown to have Helicobacter pylori, then eradication is indicated."

\section{KEYWORDS}

Dyspepsia, Acid Peptic Disease, Helicobacter Pylori, Urease, Giemsa, Peptic Ulcer, Non-Ulcer Dyspepsia.

HOW TO CITE THIS ARTICLE: Rajachidambaram K, Kaarthesan D. Incidence of Helicobacter pylori with acid peptic disease and malignant conditions of upper gastrointestinal tract in a tertiary centre - a prospective study. J. Evolution Med. Dent. Sci. 2016;5(35): 1998-2004, DOI: $10.14260 /$ jemds/2016/471

\section{INTRODUCTION}

- Acid peptic disease comprises of a wide spectrum of diseases, which cause considerable morbidity.

- Helicobacter pylori, a curved rod shaped bacterium has been consistently associated with patients suffering from acid peptic diseases, more in ulcer disease than in non-ulcer disease.(1)

Financial or Other, Competing Interest: None.

Submission 10-03-2016, Peer Review 23-03-2016,

Acceptance 25-03-2016, Published 30-04-2016.

Corresponding Author:

Dr. Karunamoorthy Rajachidambaram,

93G/5A Chidambaram Nagar,

Near New Bus Stand

Perambalur-621212.

E-mail: drkrajachidambaram@gmail.com

DOI: 10.14260/jemds/2016/471
- Due to this high association, it is now believed that Helicobacter pylori play an important role in the aetiopathogenesis of acid peptic disease.(2)

- Several studies have revealed the association of Helicobacter pylori in 70-75 percent of patients with dyspepsia. (3)

- Endoscopic studies have shown that Helicobacter pylori is found in 80-100 percent of patients with duodenal ulcers and 60-75 percent of patients with gastric ulcers.(4)

- Amidst these profound variations proposed by many workers in the previous studies, we have attempted to study the prevalence of Helicobacter pylori in patients undergoing upper gastro-intestinal endoscopy at our hospital and its association with acid-peptic disease. 


\section{METHODOLOGY}

- 389 cases of dyspepsia were studied clinically as per the proforma from July 2012 to April 2015.

\section{Criteria}

The inclusion and exclusion criteria were as follows.

\section{Inclusion Criteria}

1. Patients above 20 years of age.

2. Patients having chronic upper abdominal pain.

3. Patients showing symptoms of dyspepsia.

4. Patients diagnosed as having chronic gastritis, gastric/duodenal ulcers on gastro-duodenoscopy.

5. Patients on proton pump inhibitors.

6. Patients who are known cases of chronic pancreatitis.

7. Patients on NSAID's for more than one month duration.

8. Patients who have received Anti-Helicobacter pylori treatment.

\section{Exclusion Criteria}

1. Patients below 15 years of age.

2. Pregnant and Lactating women.

3. Patients with oesophageal growths on endoscopy.

4. Unwilling or unfit patients for upper gastrointestinal endoscopy.

5. Patient having acute abdominal pain.

After applying the inclusion and exclusion criteria, all the patients underwent upper gastrointestinal endoscopy. According to the endoscopy findings, the patients were divided into following groups.

1. Non-ulcer Dyspepsia:
a. Normal study.
b. Gastritis/Duodenitis.

\section{Ulcer Dyspepsia:}
a. Duodenal ulcer.
b. Gastric ulcer.
c. Carcinoma of Stomach.

In this study, there were cases of oesophageal carcinoma which were excluded from the study. There were 62 cases which had features of both gastritis and duodenitis. There were 11 cases of duodenal ulcer, which additionally showed features of gastritis or duodenitis or both.

\section{AIMS OF THE STUDY}

1. To study the prevalence of Helicobacter pylori in patients with dyspepsia undergoing upper gastrointestinal endoscopy.

2. To study the association of Helicobacter pylori with acid peptic diseases and malignant conditions of upper gastrointestinal tract.

\section{Review of Literature}

We have also compared our studies with other studies done previously. A brief outline of the studies compared is given below.

Marshall and Warren. ${ }^{5}$ (1984) observed that 18 out of 22 (81\%) patients with gastric ulcer and all the $13(100 \%)$ patients with duodenal ulcers were positive for Helicobacter pylori.
In 59 patients with gastro/duodenitis, 32 were positive for Helicobacter pylori (54.735). In patients with normal upper GI endoscopy, 8 out of $16(50 \%)$ were positive for Helicobacter pylori.

In their Study of 180 Patients, Von Wulfen et al (1986), found an overall Positivity in 98 Patients (54\%)

- $\quad$ They observed that in patients with duodenal ulcers, 45 out of 54 patients $(83 \%)$ showed Helicobacter pylori, while 13 out of $18(73 \%)$ patients with gastric ulcers showed Helicobacter pylori.

- 79 out of 127 patients with gastritis/duodenitis were positive for Helicobacter pylori (62\%).

- Studies (Vaira et al, 1994; Sobala et al, 1991; Patel et al, 1994) 55 were generally similar in design, in that they all have looked at consecutive patients with dyspepsia presenting for endoscopy and reported their results in terms of endoscopic finding with regard to antibody status for $\mathrm{H}$. pylori.

- Combining the studies provided a much larger sample of 631 patients, in which overall 351 patients (55.63\%) were positive for Helicobacter pylori. In these studies, out of 64 patients with duodenal ulcers, 59 patients (92.19\%) were tested positive for Helicobacter pylori, while in 30 patients with gastric ulcers 25 (83.33\%) were positive for H. pylori; 121 patients (57.62\%) out of 210 patients with gastritis/duodenitis were positive for H. pylori.

- In the present study, the overall positivity for $\mathrm{H}$. pylori was 190 out of 399 patients (47.6\%). This result is slightly lower than the results of the other studies.

- However, it is comparable to the results of the study by Tytgat GN 56 in which, the prevalence of Helicobacter pylori is decreasing worldwide, probably due to improved hygiene, increased awareness regarding $\mathrm{H}$. pylori and increase in consumption of antimicrobials.

- The incidence of H. pylori is higher in patients with ulcer dyspepsia $(75.51 \%)$ when compared to patients with non-ulcer dyspepsia (39.7\%).

- This result is comparable to those of the other studies. In the duodenal ulcer sub-group, 22 out of 25 patients (88\%) showed positivity for H. pylori. In our study, there was significant association of Helicobacter pylori with duodenal ulcers and malignant conditions as per the Chisquare test. This study can be comparable with the other studies.

- Results of gastric ulcer sub-group indicated that 10 out of 14 patients $(71.42 \%)$ were infected with H. pylori. As per the Chi-square test, this was a significant association and was comparable with the previous studies.

- In our study we also found 20 cases of carcinoma stomach, out of which 15 cases (75\%) proved to be $\mathrm{H}$. pylori positive.(5)

- This association was not significant as per the Chi-square test.

- This is in accordance with the results of the study by Van Zanten et al, 31 which showed only a moderate epidemiologic evidence of an association between chronic $\mathrm{H}$. pylori infection and gastric cancer.(6)

- In patients with peptic ulcer disease, patients with duodenal ulcer have higher incidence of Helicobacter pylori $(88 \%)$, when compared to patients with gastric ulcer (71.42\%) similar to other studies. 
- But why Helicobacter pylori which colonizes the gastric antrum is associated more with duodenal ulcers is not clearly explained till now.

- It may be because of the hyperacidity that usually is seen associated with duodenal ulcers, which offers a favourable environment for the Helicobacter pylori to thrive.

- In 172 patients who were positive for Helicobacter pylori, only 37 patients developed peptic ulcer disease (21.51\%).

- $\quad$ The remaining $78.48 \%$ patients even though harbouring Helicobacter pylori did not have peptic ulcer disease.

- The development of peptic ulcer may be because of infection with virulent strains of Helicobacter pylori.

- A vacuolizing cytotoxin is more commonly present in Helicobacter pylori isolated from duodenal ulcer patients.

- This is proposed to be the cause of duodenal ulcer disease. But, till now no toxin or virulent strains of Helicobacter pylori is proved to be the cause of peptic ulcer disease.

- In non-ulcer dyspepsia group, the patients with gastritis/duodenitis had high incidence of $\mathrm{H}$. pylori positivity (43.19\%) when compared to patients with normal upper GI endoscopy.

- Marshall and Warren (1984) were the first to describe the relationship of $\mathrm{H}$. pylori to gastritis.

- In their study, they observed an overall positivity of $54 \%$ in patients with gastritis/duodenitis. This group of patients in our study had a positivity rate of $43.19 \%$, which was not significant as per the chi square test.

- In our study, the rapid urease test had a sensitivity of $96.34 \%$ and specificity of $93.78 \%$ when compared with histopathology. This is comparable with the results of the study done by Tokunaga et al.

All our observations in the present study are comparable to other studies except for the overall prevalence of Helicobacter pylori and the percentage of gastritis/duodenitis patients with H.pylori positivity, which was less when compared to the other studies.

\section{RESULT}

- In this prospective study conducted in Chennai Medical College Hospital and Research Institute to find the prevalence of Helicobacter pylori in dyspeptic patients undergoing upper GI endoscopy, the overall positivity for Helicobacter pylori was $44.21 \%$.

- In ulcer dyspepsia group, $75.51 \%$ of the patients were positive for Helicobacter pylori; $88 \%$ of patients with duodenal ulcers and $71.42 \%$ of patients with gastric ulcers were positive for Helicobacter pylori.

- In non-ulcer dyspepsia, $39.7 \%$ of the patients were positive for Helicobacter pylori, out of which about $34 \%$ had normal endoscopic findings and $43 \%$ patients showed features of gastritis/duodenitis.

\section{From the present study it is evident that:}

1. Helicobacter pylori is significantly associated with peptic ulcer disease and carcinoma stomach than non-ulcer dyspepsia.
2. In patients who were positive for Helicobacter pylori, only a small subset of patients had ulcer dyspepsia (21.52\%). This could be because the patients with ulcer dyspepsia may be infected with virulent strains of Helicobacter pylori. But till now, no virulent factors have proven responsible for ulcer dyspepsia.

Thus further evaluation is required to discover diagnostic tests for virulent strains of $\mathrm{H}$. pylori, so that treatment can be directed towards them only.

\section{RESULT}

- In this prospective study conducted in Chennai Medical College Hospital and Research Institute to find the prevalence of Helicobacter pylori in dyspeptic patients undergoing upper GI endoscopy.(7), the overall positivity for Helicobacter pylori was $44.21 \%$.

- In ulcer dyspepsia group, $75.51 \%$ of the patients were positive for Helicobacter pylori; $88 \%$ of patients with duodenal ulcers and $71.42 \%$ of patients with gastric ulcers were positive for Helicobacter pylori.

- In non-ulcer dyspepsia $39.7 \%$ of the patients were positive for Helicobacter pylori, out of which about $34 \%$ had normal endoscopic findings and $43 \%$ patients showed features of gastritis/duodenitis.

From the present study it is evident that:

1. Helicobacter pylori is significantly associated with peptic ulcer disease and carcinoma stomach than non-ulcer dyspepsia.(8)

2. In patients who were positive for Helicobacter pylori, only a small subset of patients had ulcer dyspepsia $(21.52 \%)$. This could be because the patients with ulcer dyspepsia may be infected with virulent strains of Helicobacter pylori. But till now no virulent factors have proven responsible for ulcer dyspepsia.

Thus further evaluation is required to discover diagnostic tests for virulent strains of $\mathrm{H}$. pylori, so that treatment can be directed towards them only.

\section{DISCUSSION}

- $\quad$ Out of 389 patients there were 247 male patients and 142 female patients, age ranging from 15 years to 60 years (Mean- 41.8).

- Out of 389 patients, 172 patients were diagnosed to have been infected with Helicobacter pylori (44.21\%).

- $\quad$ All these patients presented to our hospital with upper abdominal pain or discomfort; 99 patients presented with nausea or vomiting out of which 37 had Helicobacter pylori infection.

- 25 patients had haematemesis, out of which 10 patients were positive for Helicobacter pylori infection.

- 19 patients had melena, out of which 13 turned out to be Helicobacter pylori positive; 19 patients also had loss or weight or appetite on presentation. Of them, 7 patients were positive for Helicobacter pylori.

- On examination of these patients, 59 patients were anaemic out of whom 30 patients were positive for Helicobacter pylori.

- Of these 389 patients, 300 patients had epigastric tenderness on palpation and 4 patients had an epigastric mass palpable. 
- Of these 300 patients 151 patients were tested positive for Helicobacter pylori and of those 4 patients who had an epigastric mass, only 3 patients were positive for Helicobacter pylori [Table 3], [Graph 1].

\begin{tabular}{|c|c|c|c|}
\hline $\begin{array}{c}\text { Clinical } \\
\text { Presentation }\end{array}$ & $\begin{array}{c}\text { Number } \\
\text { of Cases }\end{array}$ & $\begin{array}{c}\text { H. pylori } \\
\text { Positive }\end{array}$ & Percentage \\
\hline $\begin{array}{c}\text { Abdominal } \\
\text { pain/discomfort }\end{array}$ & 389 & 171 & 44.07 \\
\hline Nausea/Vomiting & 99 & 37 & 37.37 \\
\hline Haematemesis & 25 & 10 & 40.00 \\
\hline Melena & 19 & 13 & 68.42 \\
\hline $\begin{array}{c}\text { Loss of } \\
\text { Weight/Appetite }\end{array}$ & 19 & 7 & 36.84 \\
\hline Anaemia & 59 & 30 & 50.84 \\
\hline Epigastric mass & 4 & 3 & 75.00 \\
\hline $\begin{array}{c}\text { Epigastric } \\
\text { tenderness }\end{array}$ & 300 & 151 & 50.33 \\
\hline
\end{tabular}

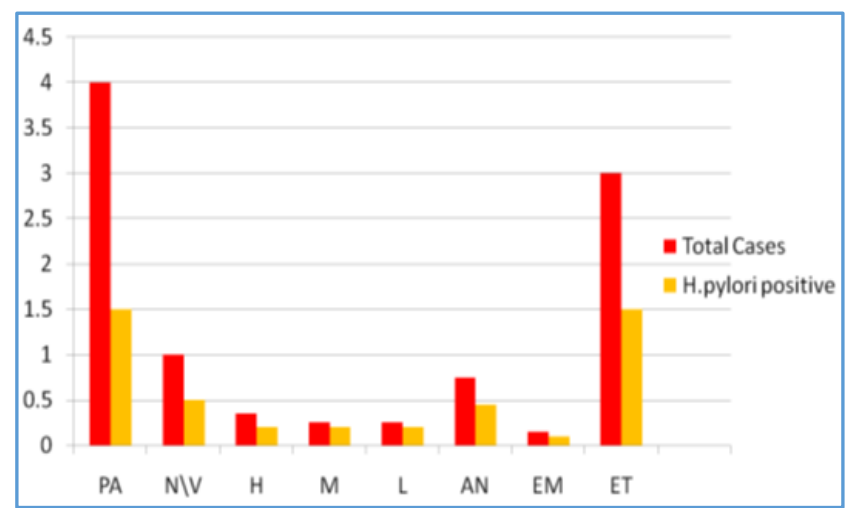

Depending on the endoscopic findings, all these patients were categorized into 2 groups [Table 4], [Graph 2].

\section{A]. Ulcer Dyspepsia}

\section{B]. Non-Ulcer Dyspepsia}

20 cases of carcinoma stomach were included in the ulcer dyspepsia group.

\begin{tabular}{|c|c|c|c|}
\hline Cases & $\begin{array}{c}\text { Total } \\
\text { Number }\end{array}$ & $\begin{array}{c}\text { H.pylori } \\
\text { Positive }\end{array}$ & Percentage \\
\hline $\begin{array}{c}\text { Ulcer } \\
\text { Dyspepsia }\end{array}$ & 49 & 37 & 75.51 \\
\hline $\begin{array}{c}\text { Non-Ulcer } \\
\text { Dyspepsia }\end{array}$ & 340 & 135 & 39.7 \\
\hline
\end{tabular}

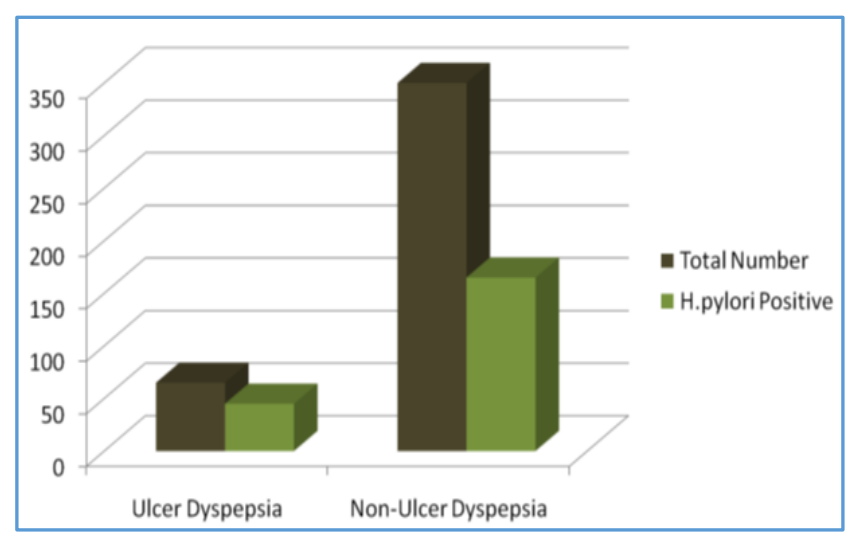

\begin{tabular}{|c|c|c|c|}
\hline Cases & Male:Female & Age Range & Mean Age \\
\hline $\begin{array}{c}\text { Ulcer } \\
\text { Dyspepsia }\end{array}$ & $30: 19$ & $15-60$ yrs. & 49.57 \\
\hline $\begin{array}{c}\text { Non-Ulcer } \\
\text { Dyspepsia }\end{array}$ & $214: 126$ & $15-60$ yrs. & 40.56 \\
\hline
\end{tabular}

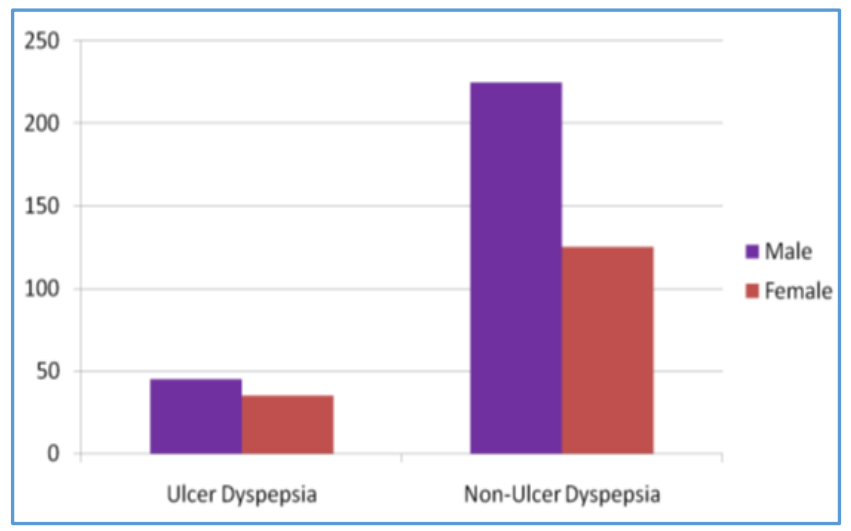

\section{ULCER DYSPEPSIA}

- In this group there were 49 patients, out of which there were 30 males and 19 females. The age range was from 15 years to 60 years (Mean- 49.57) [Graph 3].

- 37 out of these 49 patients were infected with Helicobacter pylori (75.51\%). This group was further divided into 3 subgroups [Graph 4].

1. Duodenal Ulcer.

2. Gastric Ulcer.

3. Carcinoma Stomach.

- Out of 25 patients, 16 males and 9 females who had duodenal ulcer, there were 22 patients were infected with Helicobacter pylori (88.00\%). There were 15 male patients and 7 female patients in this group.

- The age range was from 15 years to 60 years (Mean47.12). On Chi-square test, $\chi 2=25.01, p<0.01$, hence there is a significant association of Helicobacter pylori with duodenal ulcers.(9)

\section{Gastric Ulcer}

- There were 14 patients, 9 males and 5 females who had gastric ulcer, of which 10 patients were infected with Helicobacter pylori (71.42\%). In this group, there were 6 males and 4 female patients.

- Their age range was from 15 years to 60 years (Mean50.36). On applying Chi-square test, $\chi 2=7.59, p<0.01$, thus we found a significant association of Helicobacter pylori with gastric ulcers in our study.

\section{Carcinoma Stomach}

- Out of 20 cases of carcinoma stomach that were diagnosed, there were 16 males and 4 females out of which 13 males and 2 females were positive for Helicobacter pylori (50\%).

- The age range was $>15$ years (Mean- 54.6). On Chisquare test, $\chi 2=3.81, \quad \mathrm{p}<0.05$, hence significant association was found between Helicobacter pylori and gastric cancer in our study. 


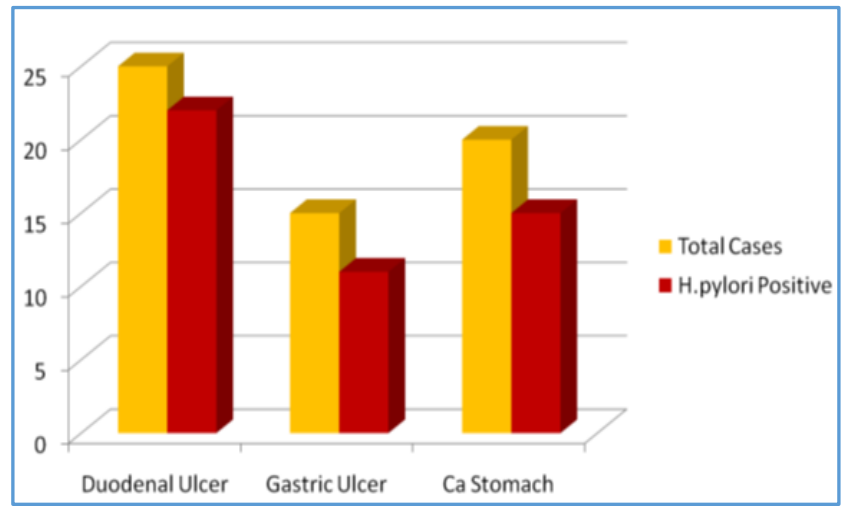

\section{Non-Ulcer Dyspepsia}

- In this group, there were 340 patients out of which 138 patients were infected with Helicobacter pylori (40.58\%). There were 214 male patients and 126 female patients in this group. The age range was $>15$ years (Mean-40.56).

- $\quad$ This group was further divided into [Graph 5].

1. Normal Study.

2. Gastritis/Duodenitis/Ca Stomach.

\section{Normal Study}

- These patients presented symptoms of dyspepsia, but the upper GI endoscopy was normal. There were 127 patients in this group, out of which 43 were found to be positive for Helicobacter pylori infection (33.85\%).

- Out of 127 patients, 72 were males and 55 were females. The age range was from 15 years to 60 years (Mean42.45).

\section{Gastritis/Duodenitis/Ca Stomach}

- In this subgroup there were 213 patients, of which 92 were infected with Helicobacter pylori (43.19\%). There were 145 males and 68 females. The age range was $>15$ years (Mean-39.44). On Chi-square test, $\chi 2=1.06$, $p>0.01$, hence there was no significant association between Helicobacter pylori and gastritis/duodenitis in our study.

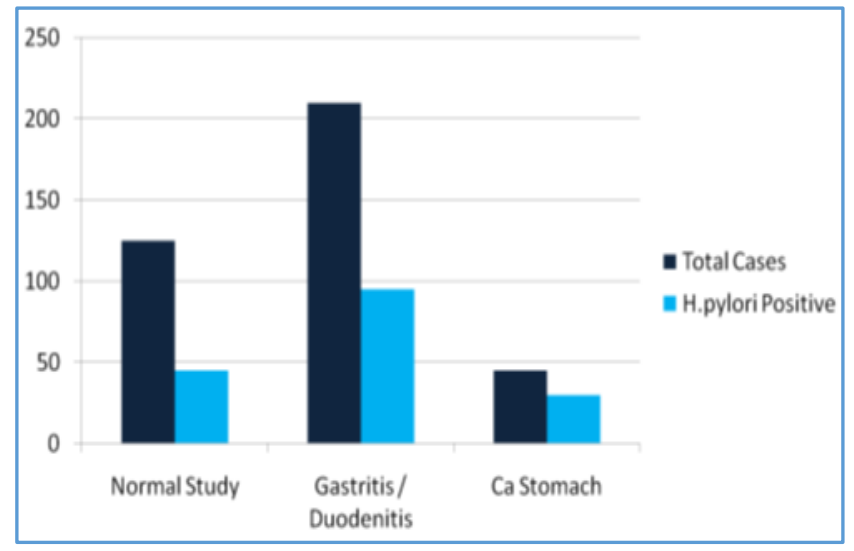

- Out of the 172 patients with Helicobacter pylori infection, 37 had Ulcer Dyspepsia (21.14\%).

- $\quad$ Remaining 135 patients (78.48\%) even though having Helicobacter pylori infection did not have ulcer diseases.
- Out of the 172 patients who were H. pylori positive, 14 patients were negative for rapid urease test, but positive for the histopathological examination and Giemsa staining (False negative).

- There were also 6 cases which were positive for the rapid urease test, but negative on histopathological examination (False positive).

- Thus in our study, rapid urease test had a sensitivity of $96.34 \%$ and specificity of $93.78 \%$ when compared with histopathology.

- In the histopathological tests, out of 166 positive cases 157 cases were positive for both H\&E and Giemsa staining.

- 9 cases were negative on H\&E staining, but positive on Giemsa staining, whereas all positive cases of Giemsa staining were also positive for H\&E staining.

- Thus H\&E and Giemsa stains were in accordance with each other in $94 \%$ cases.

\begin{tabular}{|c|c|c|c|}
\hline Cases & $\begin{array}{c}\text { Total } \\
\text { Number }\end{array}$ & $\begin{array}{c}\text { H. pylori } \\
\text { Positive }\end{array}$ & Percentage \\
\hline Normal Study & 127 & 43 & 33.85 \\
\hline $\begin{array}{c}\text { Gastritis/ } \\
\text { Duodenitis }\end{array}$ & 213 & 92 & 43.19 \\
\hline Duodenal Ulcer & 25 & 22 & 88.00 \\
\hline Gastric Ulcer & 14 & 10 & 71.42 \\
\hline $\begin{array}{c}\text { Carcinoma of the } \\
\text { Stomach }\end{array}$ & 20 & 15 & 75.00 \\
\hline
\end{tabular}

\begin{tabular}{|c|c|c|c|c|}
\hline $\begin{array}{c}\text { Age } \\
\text { Groups }\end{array}$ & $\begin{array}{c}\text { Mean } \\
\text { Age }\end{array}$ & $\begin{array}{c}\text { Total } \\
\text { Cases }\end{array}$ & $\begin{array}{c}\text { H. pylori } \\
\text { Positive }\end{array}$ & Percentage \\
\hline $15-30$ & 25.22 & 102 & 41 & 40.19 \\
\hline $31-40$ & 35.54 & 77 & 29 & 37.66 \\
\hline $41-50$ & 46.01 & 87 & 37 & 42.52 \\
\hline $51-60$ & 56.15 & 123 & 65 & 52.84 \\
\hline $15-60$ & 44.7 & 389 & 172 & 44.21 \\
\hline
\end{tabular}

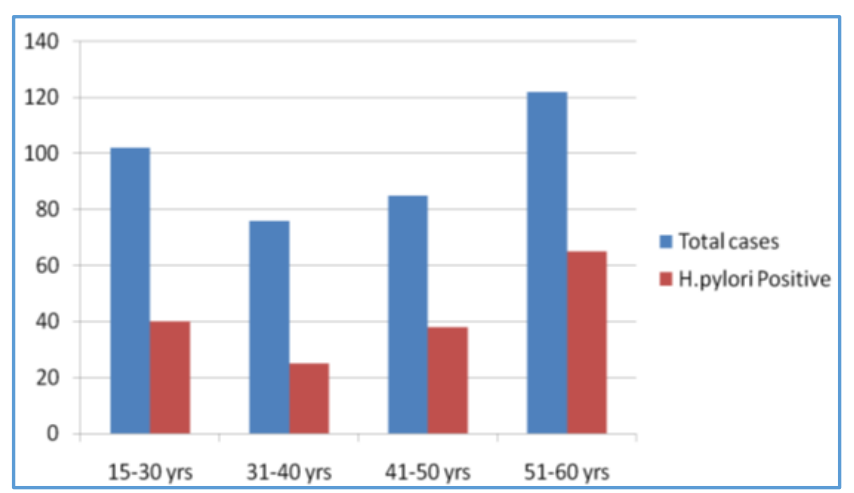

\begin{tabular}{|c|c|c|}
\hline $\begin{array}{c}\text { Endoscopic } \\
\text { Findings }\end{array}$ & $\begin{array}{c}\text { H. pylori } \\
\text { Positive }\end{array}$ & Percentage \\
\hline Normal Study & 43 & 25.00 \\
\hline Gastritis/Duodenitis & 92 & 53.48 \\
\hline Duodenal Ulcer & 22 & 12.79 \\
\hline Gastric Ulcer & 10 & 5.81 \\
\hline Ca Stomach & 15 & 8.72 \\
\hline TOTAL CASES & $\mathbf{1 7 2}$ & $\mathbf{1 0 0}$ \\
\hline
\end{tabular}




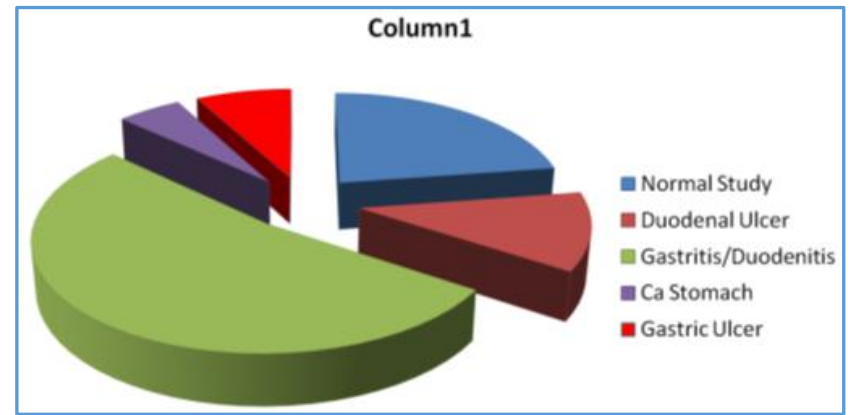

\section{PROFORMA}

\section{Case Serial Number:}

$\begin{array}{ll}\text { Name: } & \text { Age: Sex: } \\ \text { Occupation: } & \end{array}$

\section{COMPLAINTS:}

\section{DURATION:}

\section{History of Present Illness:}

\section{Pain}
a) Duration.
b) Nature.
c) Site.
d) Radiation.
e) Relation to food habits.
f) Aggravating/Relieving factors.
g) Periodicity.

\section{Vomiting}
a) Number.
b) Contents.
c) Relation to food.
d) Relation to pain.

3. Haematemesis and Melena.

4. Loss of Weight and Appetite.

- Past History:

- Treatment History:

History of NSAIDs/Corticosteroid Usage

- Personal History:

1. Diet:

2. Appetite:

3. Bowel habits:

4. H/o smoking:

Vegetarian/Mixed.

Yes/no, duration, number/day.

\section{General Physical Examination}

Built:

Nourishment:

Pallor:

Per Abdomen:

\section{Other Systems:}

\section{CVS}

CNS

\section{Clinical Diagnosis:}

Endoscopic findings:

Rapid urease test:

Special staining (Giemsa):

Other investigations if any:

\section{CONCLUSION}

- This was a prospective study conducted to determine the role of Helicobacter pylori in acid peptic diseases.

- This study design was based on clinical study and endoscopic biopsy from gastric mucosa and duodenal mucosa (whenever necessary) in 389 patients with a history of dyspepsia.

- Endoscopy confirmed the diagnosis. Rapid urease test.(10) and Giemsa staining were conducted on endoscopy biopsy specimens and Helicobacter pylori positivity was based on either rapid urease test and histopathological examination was positive.

- From the present study, it is evident that there was no specific symptom attributable to $H$. pylori infection.

- Helicobacter pylori is consistently associated with peptic ulcer disease than non-ulcer dyspepsia, which is in broad agreement with the studies done earlier. Thus, we conclude that Helicobacter pylori infection may have a role in the aetiopathogenesis of peptic ulcer disease.

- Helicobacter pylori have a role in the aetiopathogenesis of Carcinoma Stomach.(11)

- There appears to be no significant association between Helicobacter pylori infection and unexplained dyspepsia. This finding does not exclude the possibility that a small undefined subset of infected individuals will have symptoms induced by the infection, but only large randomized trials will be able to establish this.

- Hence, we recommend eradication of the bacteria only in patients positive for the bacterium, who have peptic ulceration.(8)

We believe in, Peter C Robin's Dictum:

"If a person with peptic ulcer disease is shown to have Helicobacter pylori, then eradication is indicated."

\section{REFERENCES}

1. Tomb JF, White 0 , Kerlavage AR, et al. The complete genome sequence of the gastric pathogen helicobacter pylori. Nature 1997;388(6642):539-47.

2. Steer HW, Colin-Jones DG. Mucosal changes in gastric ulceration and their response to carbenoxolone sodium. Gut 1975;16(8):590-7.

3. O'morain C, Buckley M. Helicobacter pylori and dyspepsia. Scandinavian Journal of Gastroenterology 1996;31(214):28-30.

4. Marshall BJ, Warren JR. Unidentified curved bacilli in the stomach of patients with gastritis and peptic ulceration. The Lancet 1984;1(8390):1311-5.

5. The Eurogast Study Group. An international association between helicobacter pylori infection and gastric cancer. The Lancet 1993;341(8857):1359-62.

6. Forman D, Newell DG, Fullerton F, et al. Association between infection with helicobacter pylori and risk of gastric cancer: evidence from a prospective investigation. BMJ 1991;302(6788):1302-5.

7. Silverstein MD, Petterson T, Talley NJ. Initial endoscopy or empirical therapy with or without testing for helicobacter pylori for dyspepsia: a decision analysis. Gastroenterology 1996;110(1):72-83.

8. McColl K, Murray L, El-Omar E, et al. Symptomatic benefit from eradicating helicobacter pylori infection in patients with nonulcer dyspepsia. New England Journal of Medicine 1998;339(26):1869-74. 
9. Jain A, Buddhiraja S, Khurana B, et al. Risk factors for duodenal ulcer in north India. Trop Gastroenterol 1999;20(1):36-9.

10. Tokunaga Y, Shirahase H, Yamamoto E, et al. Modified rapid urease test for helicobacter pylori detection in relation to an immunohistochemical stain. Journal of Gastroenterology and Hepatology 2000;15(6):617-21.
11. Sipponen $P$, Hyvärinen $H$. Role of helicobacter pylori in the pathogenesis of gastritis, peptic ulcer and gastric cancer. Scandinavian Journal of Gastroenterology 1993;28(196):3-6. 